\title{
Comunicação
}

[Communication]

\section{Associação entre sorologia para Neospora caninum e taxa de prenhez em vacas receptoras de embriões}

\author{
[Association between seropositivity for Neospora caninum and pregnancy rate in bovine \\ receipts submitted to embryo transfer technology] \\ G.F.Paz' ${ }^{1}$ R.C. Leite $^{2}$, M.A. Rocha ${ }^{2}$ \\ ${ }^{1}$ Centro de Pesquisas René Rachou - FIOCRUZ - MG \\ Av. Augusto de Lima, 1715 \\ 3019-0002 - Belo Horizonte, MG \\ ${ }^{2}$ Escola de Veterinária - UFMG - Belo Horizonte, MG
}

O protozoário Neospora caninum tem sido responsável por perdas reprodutivas em rebanhos de várias partes do mundo (Dubey, 1999; Santos et al., 2005). Em programas de transferência de embrião bovino não se conhece o impacto de $N$. caninum nos índices reprodutivos das receptoras de embrião, principalmente relacionados à reabsorção embrionária e aborto no início da gestação. $\mathrm{O}$ uso intensivo de receptoras sem um teste sorológico para $N$. caninum representa um potencial risco biológico para introduzir o agente em rebanhos livres de infecção, ou aumentar a prevalência desse agente em rebanhos com baixa prevalência, uma vez que a principal forma de transmissão para os bovinos tem sido a vertical com eficiência de até 95\% (Davison et al.,1999).

Os objetivos deste trabalho foram: estudar a ocorrência de anticorpos anti $N$. caninum em um rebanho de novilhas, receptoras de embrião, criadas em sistema extensivo no estado do Mato Grosso do Sul e avaliar a taxa de prenhez das receptoras soropositivas para $N$. caninum, transferidas por apenas um serviço. Os experimentos foram realizados em duas fazendas, A e B, de criação extensiva de bovinos de corte destinados ao programa de transferência de embrião. $\mathrm{Na}$ fazenda $\mathrm{A}$ ocorreu a cria e a recria das novilhas em regime extensivo. As demais etapas do estudo foram realizadas na fazenda B.
Foi feita uma triagem sorológica em um rebanho de 275 novilhas mestiças Nelore e Simental. Os animais foram testados para a pesquisa de $\operatorname{IgG}$ 1,2 anti- $N$. caninum utilizando-se um kit de ELISA indireto competitivo monoclonal de origem comercial ${ }^{1}$. Segundo o fabricante, o teste apresenta sensibilidade de $97,6 \%$ e especificidade de 98,6\%. Após a triagem, as novilhas foram divididas aleatoriamente em dois grupos de 33 animais, sendo um grupo soropositivo e o outro soronegativo para o $N$. caninum (grupo controle).

O cálculo amostral para a divisão dos grupos foi realizado de acordo com Sampaio (2002). Os animais do grupo soronegativo foram acompanhados mensalmente por sorologia até o término do experimento. Os dois grupos permaneceram juntos durante todo o experimento em uma mesma condição de manejo.

As transferências de embriões foram realizadas na fazenda $\mathrm{B}$ de acordo com as normas do Manual da Sociedade Internacional de Transferência de Embriões (Stringfellow e Seidel, 1998). O diagnóstico de gestação foi realizado por volta de 50 dias após a data do cio da receptora, pelo método de ultra-som, quando foi investigada a presença do batimento cardíaco do feto. 
Os dados foram analisados estatisticamente utilizando o teste dispersão de frequência qui quadrado (Sampaio, 2002).

Das 275 novilhas estudadas 29,5\% (81) foram soropositivas para o $N$. caninum, demonstrando uma alta ocorrência desse agente no rebanho de novilhas que são usadas como receptoras de embrião. Este resultado está de acordo com as taxas de prevalência de anticorpos para $N$. caninum encontradas em bovinos de várias regiões do mundo, que variam entre 7,6 a 30,13\% (Almeida, 2004; Ogawa et al., 2005; Aguiar et al., 2006; Bañales et al., 2006; Hall et al., 2006; Liu et al., 2007).

A taxa de prenhez dos animais soropositivos para $N$. caninum foi de $72,7 \%$ ( 24 receptoras) e a dos animais soronegativos, $81,8 \%$ (30 receptoras). Não houve diferença significativa entre os dois grupos $\left(\chi^{2}=0,345 ; \mathrm{P}=0,5569\right)$.

A ocorrência de problemas reprodutivos devido à $N$. caninum no início do período gestacional (reabsorção embrionária e abortos no início da gestação), tem sido alvo de dúvida e preocupação para profissionais que adotam o programa de transferência de embrião. Esse fato se justifica, pois, na maioria das vezes, depois de confirmada a prenhez, as receptoras são encaminhadas para o seu destino, permanecendo nas centrais apenas até o diagnóstico de gestação.

No caso da suspeita de neosporose, a pesquisa sorológica dos animais em reprodução e um estudo da associação dessa sorologia com problemas reprodutivos, são ferramentas importantes para se chegar a um possível diagnóstico. Essa mesma metodologia de diagnóstico tem sido proposta por vários autores (Paré et al., 1996; Thurmond e Hietala, 1997; Garcia-Vazquez et al., 2005), e foi, também, utilizada neste trabalho.

Este estudo demonstrou que, nas condições estudadas, não houve associação entre a presença de anticorpos para $N$. caninum e taxa de prenhez das receptoras de embrião.

Palavras-chave: bovino, Neospora caninum, transferência de embriões, taxa de prenhez

\begin{abstract}
The association between seropositivity for Neospora caninum and pregnancy rate in cows belonging to a surrogate herd submitted to embryo transfer technology was determined. The serological status was evaluated in 275 heifers, aging from 14 to 20-month-old. For N. caninum serology analysis of a monoclonal competitive ELISA test Kit was used, and 81 animals (29.5\%) showed seropositive. Thus, two groups were randomly formed selecting 33 seropositive heifers and other 33 seronegative animals out of the remaining 194 animals. Seronegative animals were followed up by serological analysis until the end of the trial in order to identify persistently infected individuals. The pregnancy rate was $72.7 \%$ in the group of $N$. caninum-positive sera, and, $81.8 \%$ in the seronegative group. No significant difference was observed between groups according to Chi-square test. No association between $N$. caninum seropositivity and pregnancy rates in surrogate heifers was found.
\end{abstract}

Keywords: cattle,Neospora caninum, embryo transfer, pregnancy rate

\section{REFERÊNCIAS BIBLIOGRÁFICAS}

AGUIAR, D.M.; CAVALCANTE, G.T.; RODRIGUES, A.A.R. et al. Prevalence of antiNeospora caninum antibodies in cattle and dogs from Western Amazon, Brazil, in association with some possible risk factors .Vet. Parasitol., v.142, p.71-77, 2006.
ALMEIDA, M.A.O. Epidemiologia de Neospora caninum. Rev. Bras. Parasitol. Vet., v.13, p.3840, 2004.

BAÑALES, P.; FERNANDEZ, L.; REPISO, M.V. et al. A nationwide survey on seroprevalence of Neospora caninum infection in beef cattle in Uruguay. Vet. Parasitol., v.139, p.15-20, 2006. 
DAVISON, H.; OTTER, A.; TREES, A. Estimation of vertical and horizontal transmissionparameters of Neospora caninum infections in dairy cattle. Int. J. Parasitol., v.29, p.1683-1689, 1999.

DUBEY, J. P. Neosporosis in cattle, biology and economic impact. J. Am. Vet. Med. Assoc., v.214, p.1160-1163, 1999.

GARCIA-VAZQUEZ，Z; ROSARIO-CRUZ, R.; RAMOS-ARAGON, A. et al. Neospora caninum seropositivity and association with abortions in dairy cows in Mexico. Vet. Parasitol., v.134, p.61-65, 2005.

HALL, C.A.; REICHEL, M.P.; ELLIS, J.T. Prevalence of Neospora caninum infection in Australian (NSW) dairy cattle estimated by a newly validated ELISA for milk. Vet. Parasitol., v.142, p.173-178, 2006.

LIU, J.; YU, J.; WANG, M. et al. Serodiagnosis of Neospora caninum infection in cattle using a recombinant $\mathrm{tNcSRS} 2$ protein-based ELISA. Vet. Parasitol., v.143, p.358-363, 2007.

OGAWA, L.; FREIRE, R.L.; VIDOTTO, O. et al. Ocurrence of antibodies to Neospora caninum and Toxoplasma gondii in dairy cattle from the northern region of the Paraná State. Arq. Bras. Med. Vet. Zootec., v.57, p.313-316, 2005.

PARÉ, J.; THURMOND, M.; HIETALA, S.K. Congenital Neospora caninum infectionin dairy cattle and associated calfhood mortality. Can. J. Vet. Res,.v.60, p.133-139, 1996.

SAMPAIO, I.B.M. Estatística Aplicada à Experimentação Animal. Belo Horizonte: FEPMVZ, 2002. 265p.

SANTOS, A.P.M.E.; NAVARRO, I.T.; BRACARENSE, A.P.F.R.L. et al. Dairy cow associated with Neospora caninum and other infections agents. Arq. Bras. Med. Vet. Zootec., v.57, p.545-547, 2005.

STRINGFELLOW, D.A.; SEIDEL, S.M. (Eds). Manual da sociedade internacional de transferência de embriões: um guia de procedimento e informações gerais para uso em tecnologia de transferência de embriões enfatizando procedimentos sanitários. Illinois: Savoy, 1998. 180p.

THURMOND, M.C.; HIETALA, S.K. Effect of Neospora caninum infection in first-lactation dairy cows. J. Am. Vet. Med. Assoc., v.210, p.672-674, 1997. 